\title{
A Summary of the NASA Glenn Ballistic Impact Lab Contributions to the Columbia Accident Investigation
}

\author{
Matthew E. Melis, NASA Glenn Research Center \\ Mike Pereira Ph.D, NASA Glenn Research Center \\ Duane Revilock, NASA Glenn Research Center \\ Kelly S. Carney, Ph.D, NASA Glenn Research Center
}

Key Words: Columbia Accident, Impact, Testing, Impact Analysis

\section{SUMMARY}

On February 1, 2003, the Space Shuttle Columbia broke apart during reentry resulting in the loss of 7 crewmembers and craft. For the next several months an extensive investigation of the accident ensued involving a nationwide team of experts from NASA, industry, and academia, spanning dozens of technical disciplines.

The Columbia Accident Investigation Board (CAIB), a group of experts assembled to conduct an investigation independent of NASA, concluded in August, 2003 that the cause of the loss of Columbia and its crew was a breach in the left wing leading edge Reinforced Carbon-Carbon (RCC) thermal protection system initiated by the impact of thermal insulating foam that had separated from the orbiter's external fuel tank 81 seconds into that mission's launch. During reentry, this breach allowed superheated air to penetrate behind the leading edge and erode the aluminum structure of left wing which ultimately led to the breakup of the orbiter.

Supporting the findings of the CAIB numerous ballistic impact testing programs were conducted to investigate and quantify the physics of External Tank foam impact on the RCC wing leading edge material. These tests ranged from fundamental material characterization tests to full-scale Orbiter wing leading edge tests. Following the accident investigation, NASA turned its focus to returning the Shuttle safely to flight. Supporting this effort are many test programs to evaluate impact threats from various debris sources during ascent that must be completed for certifying the Shuttle system safe for flight.

Researchers at the NASA Glenn Ballistic Impact Laboratory have conducted several of the impact test programs supporting the Accident Investigation and Returnto-Flight efforts. This paper summarizes those activities and highlights the significant accomplishments made by this group.

\section{BACKGROUND}

On January 16, 2003, at 10:39 a.m. Eastern Standard Time, the Space Shuttle Columbia lifted off from Launch Complex 39-A at Kennedy Space Center in Florida. At approximately 82 seconds into launch, Columbia was traveling at Mach 2.46 (1,650 miles per hour) at an altitude of nearly 66,000 feet when it was struck by a large piece of foam that had separated from the shuttle's external fuel tank. The foam, decelerated by the air flow past the Orbiter, struck the left wing leading edge of Columbia, at a relative speed of 416 to 573 miles per hour, causing the breach in the leading edge thermal protection system that ultimately led to the tragedy. Two ground movie cameras captured the event. Figure 1 is an image taken from one of the movies just before the event and depicts two foam pieces separating from the bipod ramp.

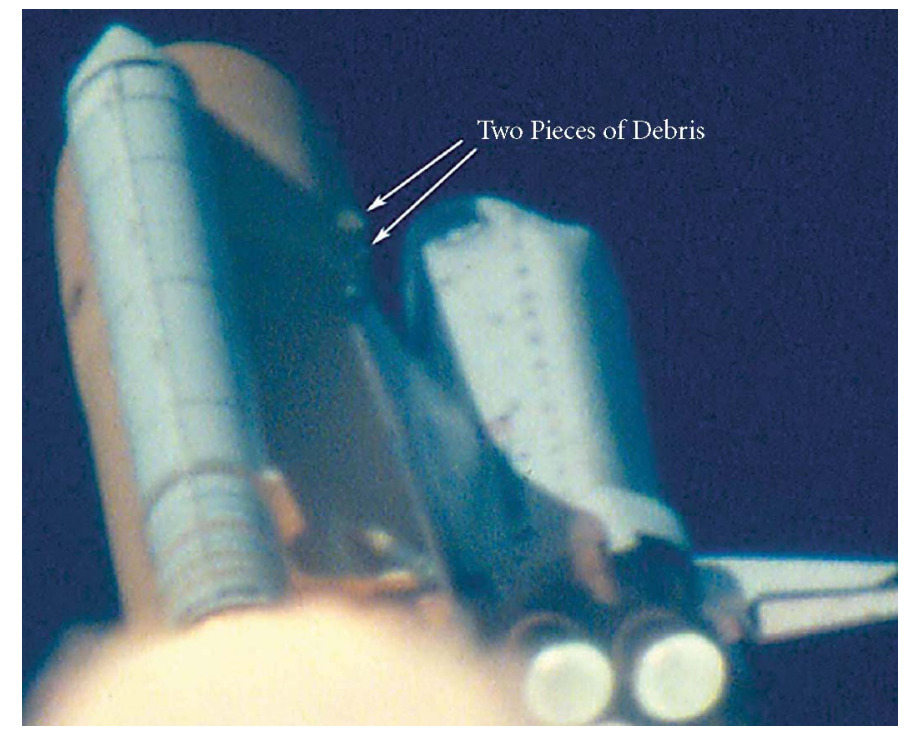

Figure 1. Two Pieces of Foam Debris Separating from Bipod Ramp.

Various types of insulating foam cover the majority of the External Fuel Tank (ET) to keep the propellants cold and prevent the formation of ice on the outside of the tank. The characteristic deep orange color of these foams is due to exposure to sunlight. Most areas on the ET require only an inch or so of foam which is typically sprayed on by machine. Some locations, however, require more substantial build-ups of foam and are applied by hand. The Bipod Attachment Struts connect the nose of the Orbiter to the ET. An additional foam buildup was required where the struts attach to the ET 
and is considered to be the source of the foam debris that impacted Columbia. The foam at this location was made from a formulation designated BX-250.

During reentry, the wing leading edges of the Orbiter can experience temperatures of up to $3000^{\circ} \mathrm{F}$ and are thermally protected through the use of a brittle plain weave ceramic matrix composite material called Reinforced Carbon-Carbon (RCC). The RCC material consists of a woven substrate and a Silicon Carbide ceramic coating to help prevent oxidation. Each orbiter wing has 22 unique RCC panels (numbered 1 through 22 from front to back on each wing) custom built for its specific location on the wing. The gaps between these panels are sealed with an RCC structure called a T-Seal.

Post accident, an exhaustive reconstruction effort of the Orbiter wreckage provided evidence of a breach in Columbia's wing leading edge due to the foam impact event. The investigation which followed quickly established the need to develop an understanding of the impact behavior of External Tank foam and Reinforced Carbon-Carbon both from an experimental and computational approach. A detailed discussion and analysis on the Columbia accident can be found in the Columbia Accident Investigation Board's report [1].

\section{THE GRC IMPACT LAB 'S ROLE IN THE ACCIDENT INVESTIGATION}

Little was known, at the time of the accident, about the impact characteristics of either BX-250 or RCC. Once it was determined that ET foam debris from the Bipod Ramp was a likely cause of the leading edge breach, the CAIB began an aggressive test program at Southwest Research Institute (SwRI) in San Antonio Texas, to build a full-scale test article of a segment of an Orbiter leading edge for impact testing. RCC panels from the remaining Orbiters that had similar mission histories to those on Columbia were used for the testing. Figure 2 shows the test range and the full-scale test article (consisting of panels 5 through 10 with respective TSeals), respectively, at SwRI.

To support the investigation, the GRC Ballistic Impact Team was tasked with four primary technical responsibilities: 1) Validate that the full-scale tests at SwRI would be appropriate in ambient atmospheric conditions (14psi). This was derived from Columbia having been struck by the foam debris in a 1 psi environment creating the requirement to quantify the effect of ambient pressure on the dynamic behavior of BX-250. 2) To develop material models for physics based explicit finite element techniques to computationally characterize foam impact on RCC. 3) To characterize the static and impact behavior of BX-250 foam in support of this modeling effort. 4) Provide expertise in digital high speed photography to document the full-scale tests at SwRI.

\subsection{Validation of the Full-Scale Leading Edge Test Conditions}

In the early stages of the Accident Investigation, it was determined that impact testing in a 1 psi environment on BX250 foam would be necessary to validate the results of the full-scale testing. This capability did not exist within the

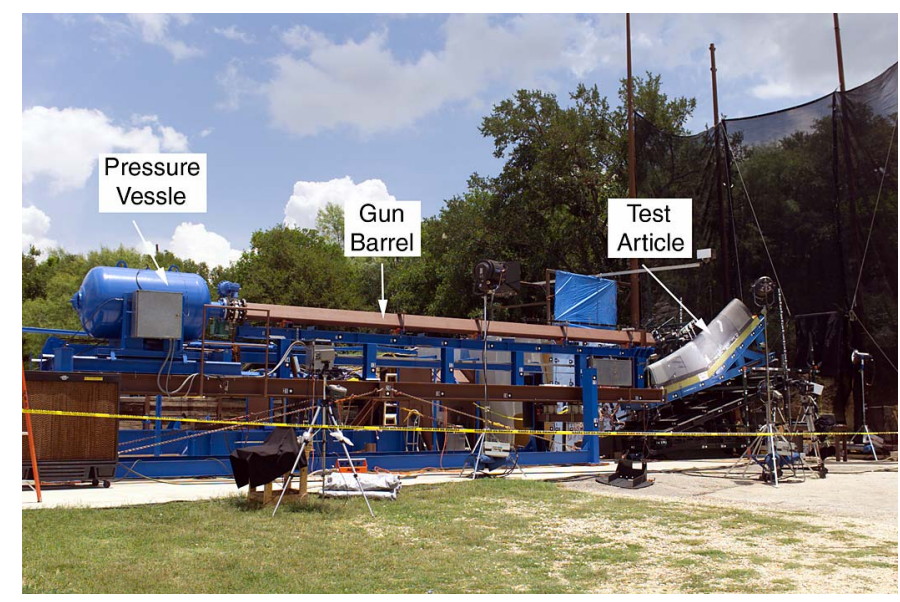

Figure 2. Ballistic test range at Southwest Research Institute showing gas gun and full-scale Orbiter leading edge test article.

Agency and the GRC Ballistic Impact Team was directed to develop such capability. The challenge was to shoot 1.25 inch diameter by 3 inch long cylindrical foam projectiles at load cells in a vacuum chamber via a gas gun and restrict the propellant gasses from entering the chamber itself. This was accomplished through the use of sabots made of polycarbonate material, seated with two O-rings at their base. At the end of the gun barrel, the sabot is stopped by a plate with a hole slightly larger than the projectile to stop the sabot while allowing the projectile to continue freely towards it's target. The plate, or sabot stopper, is positioned such that the O-rings remain inside the barrel of the gun thus containing the helium propellant from entering the vacuum. The GRC small vacuum chamber impact test apparatus is shown in Figure 3.

An extensive series of impact tests were conducted at GRC on small cylindrical samples of BX-250 at various speeds between $600-800$ feet per second at 14 psi and 1 psi. Vision Research Phantom digital high-speed cameras documented the tests and showed that the foam exhibited different characteristics at different pressures.

Figure 4 shows the comparison between two impact tests at $800 \mathrm{feet} / \mathrm{sec}$ at different pressures depicting the time history of the break-up of the foam on rebound after impact when at 1 psi vacuum. Note that the break-up is not observed in the non-vacuum condition. Although it was discovered that BX250 impact behavior was pressure dependant, force-time histories demonstrated that the impact loads were virtually identical and led to the conclusion that the full-scale tests would be valid at SwRI.

\subsection{Characterization of the Static and Dynamic Behavior of $R C C$ and $B X-250$ Foam}

Thorough static testing was performed on the BX-250 foam in the NASA GRC Fatigue Research Lab. Uniaxial stress-strain testing at cryogenic, room, and elevated temperatures was performed. In addition, the room and elevated temperature tests were conducted in atmospheric as well as 1 psi environments. 


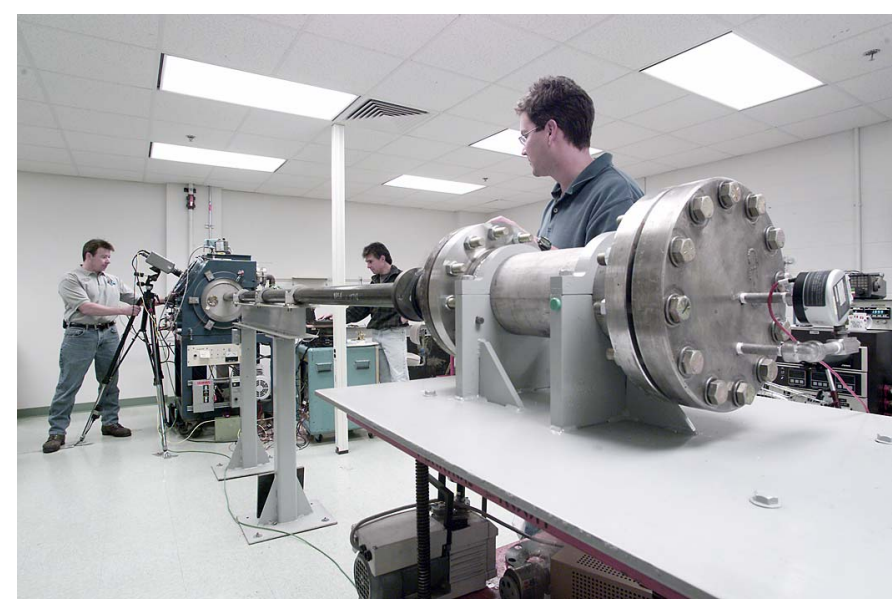

Figure 3. GRC Impact Laboratory Small Vacuum Chamber test setup.

During the accident investigation, there was virtually no RCC material available for testing. NASA GRC was able to obtain four 1.5 inch by 6 inch RCC 19 ply coupons for conducting foam impact tests with the cylindrical BX-250 projectiles. These tests helped to demonstrate impact damage thresholds to better understand the RCC resistance to impact damage. Impact tests were conducted at projectile speeds of 397, 555, 600, and 695 feet per second. Ultrasound and Pulse Thermography non-destructive evaluation (NDE) images were taken on each coupon before and after each test. At $397 \mathrm{ft} / \mathrm{sec}$, no damage to the coupon was seen either visibly or through $\mathrm{NDE}$ inspection. At 555, and $600 \mathrm{ft} / \mathrm{sec}$, the coupons were fractured partially but not broken in two. NDE inspection depicted significant internal ply delamination near the crack region. The coupon shot at $695 \mathrm{ft} / \mathrm{sec}$ was broken in two.

\subsection{Material Model Development for RCC and BX-250 Foam}

LS-DYNA, a commercial explicit finite element code, was selected as the tool to be used for the physics based analysis [2]. GRC was responsible for developing the LSDYNA material models for both the BX-250 and RCC materials. Materials subjected to impact experience high strain rates. Consequently, high strain rate materials data is required to completely develop an accurate analysis model. Obtaining high strain rate material properties requires exotic test methods which are difficult to perform for monolithic materials. The nature of RCC and BX-250 foam further complicate the process of obtaining such data.

The LS-DYNA material model for the BX-250 foam was developed from the static tests performed at GRC as well as high strain rate tests conducted at Langley Research Center. The BX-250 is a low-density elastic foam with a highly nonlinear, strain rate dependent stress-strain behavior. The RCC composite material model created for the accident investigation was initially based on limited static stress-strain data generated years earlier. This data also showed nonlinear stress-strain behavior, in addition to compressiontension asymmetry with higher stiffness and strength observed in compression.

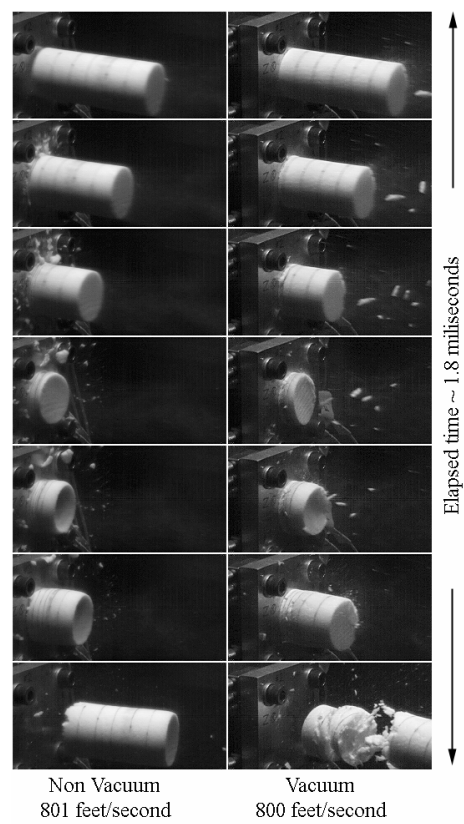

Figure 4. Comparison of BX-250 foam undergoing impact at vacuum and non-vacuum conditions.

These models were provided to the NASA/Boeing Impact Analysis Team and were used to demonstrate that a viable physics-based predictive capability with LS-DYNA could be developed for future use by the Shuttle Program. Near the conclusion of the full-scale testing at SwRI, this analysis capability was used to support decisions made in conducting those tests. Figure 5 shows the LS-DYNA predictions made correlate well with the full-scale Panel 8 test as seen in the high-speed video of the actual test.

\subsection{Support of Full-Scale Tests at SwRI}

GRC Ballistic Lab personnel were on site for the entire full-scale test series to install, setup, and run the digital highspeed cameras used internal to the leading edge test article. Many tests were performed during the full-scale test series with the most significant test performed on Panel 8 . This test shot a 1.67 pound piece of foam at 775 feet per second at the RCC Panel. The impact created a hole in the panel sixteen inches square which can be seen in the high-speed images of Figure 5. This was the last full-scale test in the accident investigation providing the final supporting evidence to the CAIB conclusions.

\section{THE GRC IMPACT LAB 'S ROLE IN THE RETURN TO FLIGHT EFFORT}

As the Accident Investigation concluded, NASA turned its attention to returning its remaining shuttle fleet to safe flying status. An adequate understanding of the potential threat of any debris impacts to the launch system would need to be developed before NASA could launch the Shuttle again.

Much of the surface area of the External Tank and Solid 

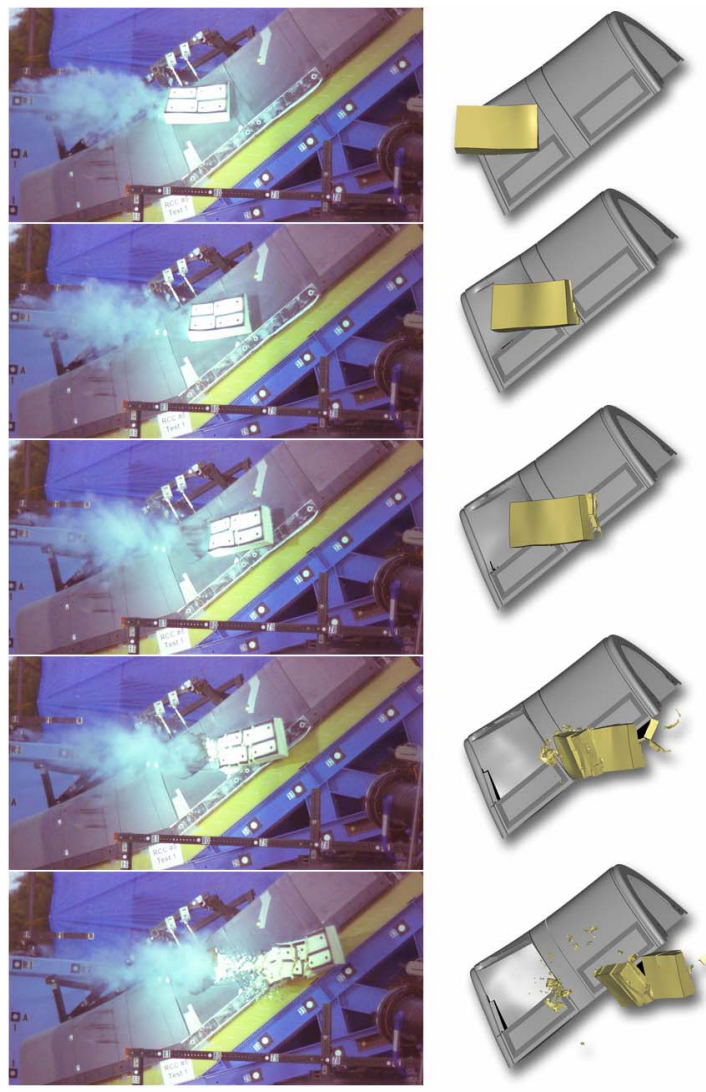

Figure 5. Comparison of LS-DYNA prediction with actual Panel 8 test at SwRI.

Rocket Boosters (SRB's) are covered with foam or ablator thermal protection system (TPS) materials. Several of these materials were identified to be potentially shed during ascent requiring their threat as a debris impact source to be characterized. The threat characterization for each of these was expanded to include not only RCC wing leading edges, but Orbiter windows, External Tank structure, and Orbiter Tile as well.

In response to these challenges, the GRC Ballistic Impact Lab took responsibility for planning and executing numerous Tasks which included several critical path elements key to the success of the Return-to-Flight program. The primary tasks were as follows: 1) Extensive impact testing and characterization of potential debris materials 2) Impact testing on orbiter windows. 3) Impact Testing on External Tank Structure. 4) Impact testing on flat RCC panels. 5) Material model development and production analysis runs for the Shuttle Program Impact Analysis Team 6.) Analysis and testing support at SwRI for phase II of the full-scale wing leading edge tests. At the time of this paper's publication, all of these programs were in progress to be completed by early 2005 for NASA's scheduled return to flight in March.

The majority of the tests for these programs were conducted in the GRC Impact Lab Large Vacuum Chamber which was specifically built for the Return to Flight effort. The chamber, seen in Figure 6 with the 3 inch round barrel, has internal dimensions of 5 inch by 4 foot $\mathrm{x} 4$ foot and can accommodate a maximum barrel dimension of 6 inches.

\subsection{Impact Testing and Characterization of Potential Debris Materials}

The TPS materials considered as potential debris sources included various foams (BX-265, NCFI, and PDL) as well as several ablators (RT 455, BTA, SLA, and MA). In addition, ice that forms on the External Tank was also included in this list. To better understand the impact threat from each of these materials, static and dynamic characterization would be performed just as was done on the BX-250 foam for the accident investigation. Although valuable to many areas in the shuttle program, the primary motivation for doing this work was to provide the foundation and material properties for LS-DYNA material models under development for each.

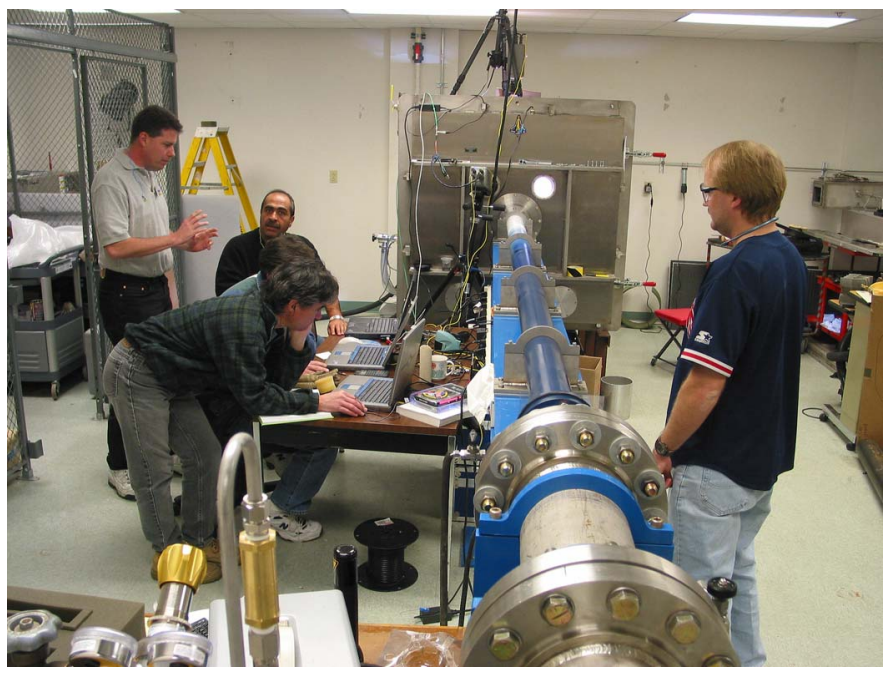

Figure 6. Large Vacuum Gun with 3 inch barrel in GRC Ballistic Lab

The GRC Fatigue Research Lab conducted comprehensive static testing at $1 \mathrm{psi}$ and atmospheric pressure of BX-265 and NCFI foams. RT 455 and BTA ablators were tested in atmospheric pressure only as it was assumed that ambient pressure would have little effect on the mechanical response of either of them. In order to account for strain-rate sensitivities, high strain-rate tests in atmospheric pressures were performed on selected foams and ablators at NASA Langley to compliment the GRC static data for the LS-DYNA model development.

Impact testing was performed on each of these materials to establish force-time histories as well as qualitative impact behavior. Results from these tests were used to demonstrate the validity of the LS-DYNA models such that reliable predictions of full scale impacts could be made with confidence.

\subsection{Orbiter Windows Impact Tests}

Each Orbiter has six sets of forward/side windows for the crew cabin. Each set is comprised of three separate windows: two redundant windows to maintain crew cabin pressure and the exterior thermal pane to protect against aerothermal loading. Minute amounts of surface damage could lead to the 
brittle fracture of the thermal pane during its mission cycle loading. Therefore, very low acceptable limits of such damage have been established for the program. Several impact threats to these windows have been identified and the GRC Impact $\mathrm{Lab}$ is conducting the tests to fully characterize each scenario.

The program is evaluating impact damage due to: $\mathrm{BX}-265$ and NCFI TPS foams separating from the ET, ice formed on the ET, aluminum oxide particulates exhausted from the Solid Rocket Booster Separation Motors (BSM's) at SRB separation, and paper rain (butcher paper) cover debris from the Orbiter's forward reaction control motors.

To clear the windows for safe flight, foam and ice projectiles for each of these materials were fired at previously flown front and side windows which had been pulled from service for various reasons. Aluminum oxide particulates were fired at window 1 inch $x 9$ inch witness coupons (MOR bars) typically used for modulus of rupture tests. These witness coupons were processed simultaneously alongside each individual window to verify processing quality. Size, velocity and angle of impact on the windows for each of the projectiles were determined by the debris transport analysis group (DTA) in the shuttle program.

Foam, paper and ice tests were performed in the Large Vacuum Chamber at GRC. Full-scale windows were mounted in an aluminum frame fixed inside the chamber at the prescribed angle to the gun barrel.

Aluminum oxide particulates of concern ranged from 100 to 450 microns and were fired at the MOR bars using the 0.125 inch vacuum gun. Each window and MOR bar was fully inspected by certified Shuttle Windows Inspectors prior to testing to identity any preexisting damage so as not to be included in the post test examination. Following each test, the windows would then be reexamined for any surface damage using a fiber-optic lighting system. Molded impressions were taken of any suspect damage sites and quantified with an optical comparator to establish whether the damage fell within or outside the acceptable safety limits.

\subsection{External Tank Structure Impact Tests}

DTA determined that External Tank BX-265, NCFI, or PDL foam debris could potentially shed and impact the tank downstream from the point of separation. Such an event might possibly result in significant TPS foam loss at the impact site which could put the launch system at risk. As with the windows, latitude of tests at varying angles, velocities, and projectile configurations were conducted at GRC to characterize TPS foam on foam impact. Target panels were made from 2' $x$ 2' aluminum plates sprayed with approximately 1" of foam to represent actual coverage on the ET. The panels were mounted in the Large Vacuum Chamber at each corner onto a load cell frame for measuring the force time history of each impact.

Both cylindrical and square projectiles were machined for this test series to establish shape sensitivity to impact damage. However, rectangular projectiles were used for the majority of this test series and were shot from square barrels using no sabot as a result of higher velocity requirements and the square barrel geometry. Figure 7 shows high speed footage of a typical impact event observed in this test series.

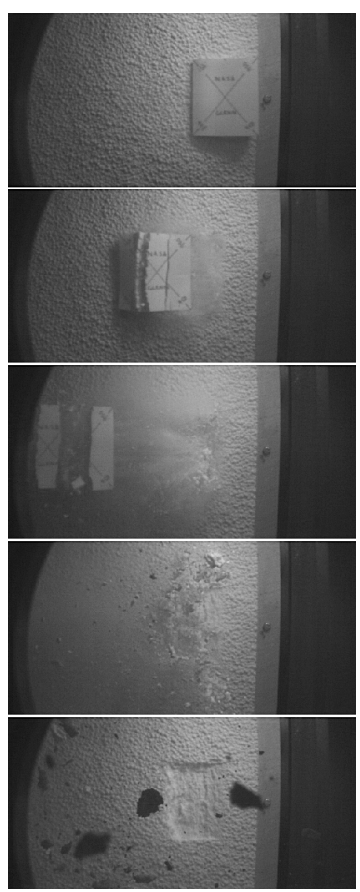

Figure 7. High-speed images of BX-250 foam projectile impacting NCFI Foam sprayed on aluminum test panel.

\subsection{RCC Flat Panel Impact Tests}

As a result of the extremely limited supply of RCC test material, this series of tests was perhaps the most significant at the GRC Impact Lab. This program was motivated by the requirement to validate the accuracy and reliability of the LSDYNA prediction capability developed under Return to Flight. RCC deformation and damage thresholds due to impact were to be quantified from these tests.

The program was designed to shoot BX-265, ablator, and ice projectiles at 6 inch $\mathrm{x} 6$ inch RCC 19 ply flat panels at 90 and 45 degrees. For each projectile, a spectrum of tests was conducted to establish both a maximum velocity at which no damage would occur as well as the minimum velocity resulting in severe damage to both the front and backside of the panel. Pre and post test, Ultrasound and Pulse Thermography NDE were done to detect internal delaminations due to impact. This was particularly important in detecting internal damage when no external visible damage was observed.

Of major significance for this test series is the method in which deformations were measured. A full-field displacement measurement system made by Trilion Systems called Aramis utilizes stereographic photogrammetry techniques to establish 3-D displacements at static and dynamic conditions. The Aramis system used in conjunction with two Phantom cameras to view the same field of interest from slightly different angles correlates synchronized high-speed images from the cameras to compute 3-D displacements. To date, displacement measurements using Aramis correlate very well with LS- 
DYNA predictions. This accomplishment with Aramis using high-speed imagery is groundbreaking and has been of high value to the Return to Flight effort. Aramis was also used for the ET foam on foam impact tests in the same manner as for the RCC panel tests.

\subsection{Ballistic Impact Analysis Team Responsibilities}

The Ballistic Impact Analysis Team assembled for the accident investigation was asked to continue its work for Return to Flight. This team, comprised of impact dynamics experts from NASA Glenn, NASA Langley, and Boeing Philadelphia, was directed to implement and validate the LSDYNA impact analysis capability and use it to quantify the threat of a spectrum of impact scenarios on wing leading edge RCC panels provided from the DTA. This evolved into an extensive parametric study of impacts (production runs) due to BX-265 foam, ablator material, and ice on several different RCC panels and T-seals of the wing leading edge with the goal of establishing impact damage thresholds.

To accomplish this, the team built detailed finite element meshes for specified RCC panels and T-seals to be used in the LS-DYNA analyses. In parallel, validated LS-DYNA material models for RCC, ice, ablator, and BX-265 foam were developed for the production runs. Hundreds of impact analyses were made with the intent to quantify the threat of each scenario provided by the DTA.

Completion of this task would be required prior to NASA's next launch. Figure 8 shows a typical analysis with foam impacting a panel and T-seal. GRC participated in all aspects of this team's activity. However, their primary responsibility was the material model development.

A comprehensive set of models representing BX-265 foam in a variety of conditions and properties was created. The data used to create these models was compiled from a series of high strain rate and static compressive tests completed at Langley Research Center and tension tests which were performed at Marshall Space Flight Center. A set of parameter studies was then performed to select the foam which would produce the greatest load, for its use in the Shuttle re-certification analysis effort.

In addition, other potential projectile materials are being modeled. These include the SRB ablators which are composed of cork and epoxy. The data used to create these models was also compiled from a series of high rate and static compressive tests completed at Langley Research Center and tension tests which were performed at Marshall Space Flight Center. Loads produced by analysis using these material models has been compared to ballistic test load data, performed at GRC, and has been found to be in excellent agreement.

A series of new tests on RCC were conducted in order to better define the RCC behavior. Static tests of RCC with and without coating were conducted at Southern Research. A series of high strain-rate tension tests using a Hopkinson-Bar Technique were conducted under grant with Ohio State University, in order to fully quantify the strain rate behavior of the RCC composite.

As mentioned in section 3.1, testing on the projectile

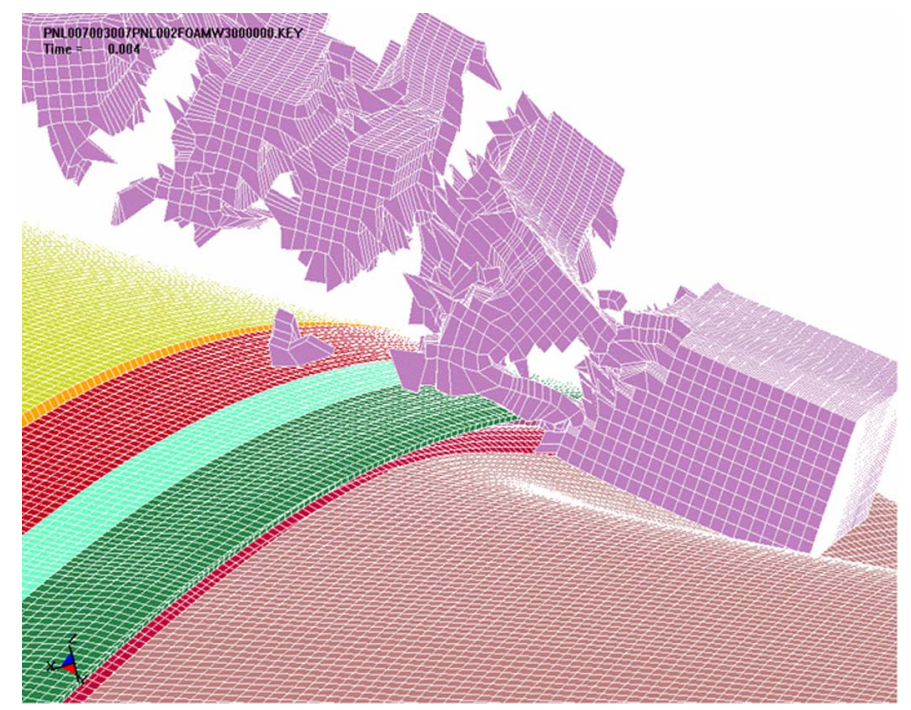

Figure 8. Foam projectile impacting RCC panel and T-seal.

materials was performed to support the development of the material models to be used for the production runs. At the time of this publication, the results of the $\mathrm{RCC} /$ foam flat panel impact tests were showing excellent displacement correlation to representative LS-DYNA predictions supporting the validity of production runs assessing foam impacts. The significance of this work has been the development of an analysis prediction capability that was non-existent prior to the Columbia tragedy and will undoubtedly be used extensively for future launch operations.

\subsection{Support of Full-Scale Leading Edge Tests at SwRI}

As a final validation of the LS-DYNA predictive capability, follow on full-scale leading edge impact tests with ice and foam projectiles will be preformed at SwRI on two Panel 9 test articles. As before, the GRC Ballistic Lab will provide high-speed digital photographic support as well as support for using the Aramis system to acquire panel deformations for each of the tests.

It is anticipated that the results from these tests will provide the data required to establish a reasonable level of confidence in the ability of LS-DYNA to accurately simulate impact events on the Shuttle leading edges.

\section{ACKNOWLEDGEMENTS}

As with most technical efforts of this magnitude, many individuals ultimately contribute to their success. Dozens at GRC and NASA-wide were key to supporting these programs. The authors wish to express their sincere appreciation for the commitment and perseverance over the last year and a half to each person, too numerous to mention here, who worked so hard to bring us where we are at today. We look forward to completing this program together with you and the ultimate celebration on the day we return the shuttle to safe flight.

\section{REFERENCES}


1. Columbia Accident Investigation Board, Volume 1, August 2003 Government Printing Office, Washington D.C.

2. Livermore Software Technology Corporation (LSTC), LS-DYNA Keyword Manual, Version 970, 2003.

\section{BIOGRAPHIES}

Matt Melis

NASA Glenn Research Center

21000 Brookpark Road

Cleveland, Ohio, 44138 USA

Email: Matthew.E.Melis@nasa.gov

Matthew Melis received both a BS in Civil Engineering and an MS in Engineering Mechanics from Michigan State University. Mr. Melis has worked at the Glenn Research Center for twenty years. His primary area of focus is in advanced finite element modeling and analysis methods including nonlinear and dynamic impact loading. His research is being used to predict ballistic impact response of jet engine fan containment concepts. Since the Columbia Accident, Matthew has been dedicated full time to the Columbia Accident Investigation and NASA's return to flight efforts.

J. Michael Pereira

NASA Glenn Research Center

21000 Brookpark Road

Cleveland, Ohio, 44138 USA

\section{Email: J.M.Pereira@grc.nasa.gov}

Dr. Michael Pereira manages the NASA Glenn Research Center's Ballistic Impact Facility. He has conducted extensive experimental research in the area of impact, penetration and high strain rate behavior of structures and materials, particularly as it applies to jet engine containment and propulsion systems. Dr. Pereira received a Ph.D. degree in Mechanical and Aerospace Engineering from Case Western Reserve University, Cleveland, $\mathrm{OH}$ in 1989, and a M.S. degree in Mechanical Engineering from The Ohio State University, Columbus, $\mathrm{OH}$ in 1981. For the last year, he has been dedicated full time to the Columbia Accident Investigation and the return to flight efforts.

Duane Revilock

NASA Glenn Research Center

21000 Brookpark Road

Cleveland, Ohio, 44138 USA

Email: Duane.M.Revilock@grc.nasa.gov

Duane Revilock has worked for NASA's Glenn Research Center, Cleveland, OH since 1989. He became an Aerospace Engineer in 1996 after receiving a B.S. and M.S. degree from Cleveland State University, Cleveland, $\mathrm{OH}$. His primary area of research has been in the area of ballistic impact testing. $\mathrm{Mr}$. Revilock was responsible for the design and development of NASA Glenn's Ballistic Impact Laboratory, a facility serving researchers in academia, government and industry. For the last year Duane has been dedicated full time to the Columbia Accident Investigation and the return to flight efforts.

Kelly S. Carney

NASA Glenn Research Center

21000 Brookpark Road

Cleveland, Ohio, 44138 USA

Email: Kelly.S.Carney@grc.nasa.gov

Kelly Carney received a BS in Mechanical Engineering from the Michigan State University, and MS from the University of Toledo, and a Ph.D. from Case Western Reserve University. Dr. Carney has worked at Glenn Research Center for twentythree years. His past experience includes analysis of launch vehicles and space structures on projects such as ShuttleCentaur, Atlas-Centaur, ACTS, and Space Station. In recent years, he has focused on the research area of ballistic impact dynamics. For the last year Dr. Carney has been assisting the Columbia Accident Investigation, and NASA's return to flight efforts 